\title{
THE EXPERIENCE OF BLACK PARENTS/CARETAKERS WITH THE BIRTHS AND CARE OF A CHILD WITH PROFOUND CONGENITAL DEFECTS

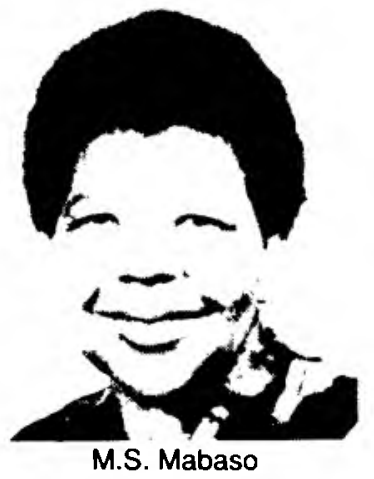

\section{S. Mabaso, L. R. Uys}

\section{INTRODUCTION}

Parents of a child born with a profound congenital defect, experience severe emotional shock at this event. In the case of Black parents there are few support services and Black parents/caretakers of these babies participate very little in voluntary support groups. These babies are discharged and do not come back to the out-patients department. The questions that arise are: what happens to these babies? Are parents coping? What support do they need?

\section{OBJECTIVES OF THE STUDY}

To determine the parents' perceptions, and attitudes to health care programmes in the long and short term.

2.2 To establish whether mothers of babies born with congenital defects identify problems in their mother/child relationships and in the rearing of a severely deformed child.

2.3 To determine the short term as well as long-term effects of the presence of a handicapped child in the family.

2.4 To assess the present available support programmes for these families.

2.5 To determine whether these parents perceive an ethical problem associated with the birth of a deformed baby.

\section{LITERATURE REVIEW}

Studies into this problem in the Black population of South Africa have not yet been undertaken, although a similar study was carried out in the white population by Venter (1986).

Mercer (1974) identified the following parental reactions to the birth of handicapped

\section{ABSTRACT}

The reaction of Black families to the birth and care of $a$ baby with profound congenital defects was researched using twenty case studies. It was found that the families went through stages of the grieving process, that they shifted from the Western/Christian viewpoint to the traditional viewpoint in their struggle to cope and that they find the existing services grossly inadequate.

\section{OPSOMMING}

Die belewenis van Swart families van die geboorte en sorg van ' $n$ baba met 'n ernstig kongenitale defek is nagevors deur twintig gevallestudies te doen. Daar is gevind dat die families deur die stadia van die rouproses gaan, dat hul beweeg van die Westers-Christelike sienswyse na die tradisionele in hul poging om die ervaring te verwerk en dat hul die beskikbare dienste baie swak vind.

child: loss of self-esteem, shame, ambivalence, depression, self sacrifice, defensiveness and disappointment at having a child with a defect. Most parents are realistically concerned with the child's future. A defective child is likely to threaten parents' self esteem because of the parents tendency to regard the child as extensions of themselves. These reactions which may be negative, ambivalent or positive may be classified into the immediate reactions of the parents, when they learn that the baby they are expecting will be deformed; and their later reactions, when the parents recover from their grieving process.

Kazak (1985), in a study that was carried out on family stress and social support networks found that the social support network of families of children with spina bifida assist the family to readjust and minimize the possibility of physical and psychosomatic disorder.

Venter (1986) quoted from Rathborne ". . . a handicapped child presents a constant source of demand on the mother both at the emotional and physical level as well as a standing reproach to the parents who have not managed to come up to usual standard".

Romney (1984) studied the effects which the child with congenital defects has on family development and parenting. The author revealed that the anticipated identity of the child is either modified strikingly or lost completely, depending on the extent and character of malformation. As a result family life is disrupted. This can be overwhelming for the parents, siblings, extended family and friends. It is suggested that to assess the needs of families dealing with infants with congenital anomalies health care providers should understand these needs and events if a healthy pregnancy, labour, delivery and post partum period is to result in healthy infants.

In a study carried out by Domer and Artwell (1985) 16 families (mean age of mother 31,3 years, mean age of father 32,9 years) were contacted 2-7 years after the death of their spina bifida babies following transfer to a specialist unit and the parents subsequent decision against active treatment. There was little evidence of serious long-term problems of adjustment in any of the measures assessing marital relationships, parental, physical and mental health and decisions about later pregnancies. Parents 
welcomed the unit's policy of encouraging frequent contact with their baby and thought that it had facilitated the grieving process. All these studies were of mothers from western culture.

\section{METHODOLOGY}

This was a qualitative study, based on indepth case studies. Information was collected from the parents or caretakers through home visits and at clinic visits. Demographic and diagnostic information which assisted in identifying the clients' type of defect, name, address, date and time of birth of the baby were obtained from the hospital records. The interviews were non-directive and no questionnaires were used. A tape-recorder was used where possible. The technique used in the Clay Model of Interaction Skills was adopted.

A random sample of 10 babies born with congenital defects was selected from the babies who were born or admitted between 1st November 1981 and 30th November 1987. Subjects were traced from the addresses in the hospital record. Where it was not possible to trace the subjects, another subject was selected until the required number of subjects was obtained. Only families from the greater Durban metropolitan area and the rural areas of Natal and $\mathrm{KwaZulu}$ within a $100 \mathrm{~km}$ radius of Durban were included in the sample frame.

Ten cases of those babies born or admitted between October 1987 to the end of the research period were also accepted into the study. These ten cases were included so that initial perceptions could be compared with those of the parents of older children.

\section{RESULTS}

The basic information about the 20 cases studied is summarized in Table 1. Each case study was finally done using the following headings:

- background

- reaction of family

- effects on family

- socio-cultural factors

- responses from health care providers

- available health care facilities

- the ethics of abortion and euthanasia.

A cross-case analysis was then done using the same headings.

\section{DISCUSSIONS AND RECOMMENDATIONS}

A discussion of the main findings follows. The short and long-term impact of a grossly malformed infant born into the family was highlighted. A comparison between the perception of parents of newborn and older children was carried out.

\subsection{Negative Responses}

\subsubsection{Negative responses are consistent with} the grieving process.

Parents and the health care providers appeared to perceive these babies in a strongly negative light.
There was consistency in both groups with expressions such as 'very hurt', 'very upset', 'it was a traumatic experience', 'we felt very bad about it' used frequently. Parents appeared apprehensive, depressed and disappointed at the arrival of this baby as observed by the research in the case of mothers of newborn babies ( 0 - $]$ years) and verbalised by mothers of older children. Most parents appeared concerned about the future of the child and they verbalised that they constantly worry about it. Stages of the grieving process as identified by Kübler Ross (1963) were revealed in varying levels of intensity. This reaction was consitent in both groups (mothers of newborns as well as older children).

\subsubsection{Denial and Shock}

Rhetorical expressions and exclamations such as 'what have I done to deserve this punishment; Why me? Oh no! I cannot believe it' could be interpreted to indicate various levels of denial and shock.

\subsubsection{Anxiety and Depression}

There were terms which were frequently verbalised by the respondents during the interview, when they explained how they reacted to the situation. Most respondents were crying when talking to the researcher. This was more noticeable in the case of mothers of newborns than of mothers of older babies. Crying is believed to confirm the feeling of anxiety and depression in performance terms as the mother feels better after crying.

\subsubsection{Bargaining}

Very many of the parents engaged in the following types of behaviour: going to faith healers and having constant prayer meetings, suddenly becoming very religious, using holy water, going from doctor to doctor and to inyangas and sangomas. Performing the proand prescribed rituals, which may be interpreted as bargaining with the powers that be, and appealing for the situation to be reversed. One respondent stated that God is capable of reversing the situation and she will continue to become more religious.

Traditional rituals are carried out in an effort to 'bargain' with the supernatural powers that are responsible. It is hoped that with the ceremony of 'amagobongo' and 'Ukushweleza' the 'Amadlozi' can reverse the situation after the cleansing ceremony (cases 13, 16, 18).

\subsubsection{Acceptance}

Acceptance would be shown by respondents who verbalised that the baby is a gift from God. If the situation cannot be reversed, the parents verbalise acceptance by stating ' $\mathrm{His}$ will be done' and accept 'His will' without questioning. The belief that if parents show resentment of the abnormality, God or their gods may be angered and give them another abnormal baby, has a strong influence on whether the child will be accepted. Acceptance has two stages, bargaining and real acceptance.

\section{(a) Bargaining Acceptance}

This is an immediate reaction to the situation which is superficial. The objective is to bargain. Bargaining acceptance is more common during the earlier stages when the parents tend to infer that they have accepted the baby as a gift from God in an effort to impress others or God himself. This is often followed by a period of bargaining, evidenced by behaviour described under 6.1.1.3.

\section{(b) Real Acceptance}

Real acceptance follows later. It is the result of the acceptance of the reality and permanence of the situation. The mother will not just say that she has accepted the baby to impress others, it will be what the mother does and how she responds to the baby that will confirm real acceptance. This can be observed over a period of time as the mother interacts and relates with the baby.

This acceptance is not a constant state which endures once it is reached. "... A handicapped child presents a constant source of demand on the mother both at an emotional and physical level as well as a standing reproach to parents who have not managed $i$ come to normal standards" (Rathborne, 1973). Venter (1986) argues both as a parent and professional "... there is nothing like acceptance. Parents need both privacy and permission to be upset".

\subsubsection{The Intensity of the Reaction of \\ Parents}

If the parents perceived the baby to have a gross abnormality, the effect was strongly negative (case 9,10 and 11). Where the parents did not perceive the baby to have an abnormality they appeared to be positive (cases 4 and 20). Many parents initially tended to hope that health care providers would be able to correct the problem. The reaction of parents appeared to be more intense in the case of mothers of newborn babies than in mothers of older babies (most of the mothers in this group cried). Some mothers of older babies were able to recall their immediate reaction of the abnormality with reasonable clarity (Case 11, 12,13 and 14) while others stated that the traumatic experience lives on throughout the life of their baby (case 16, 17, 18 and 19).

“... Adjustment should be considered within the context of a lifespan rather than a single point in time" (Crynic et al, 1983). If the baby survives beyond a year, the probability of survival to a long lifespan is possible. Where the baby dies soon after birth or shortly thereafter, parents experience a feeling of relief rather than grief at his death. Thereafter parents will always refer to their baby who died without referring to the cause of death. An early death facilitates denial.

\subsubsection{Factors Influencing the Reaction of Parents to the Situation}

The more knowledgeable the parents are about the deformity the more intense their feelings. If the parent is an assertive person, she may be able to express her feelings to staff and community effectively. But if she is less able to do this, she will be described as stoical and will have much less support. The 
less knowledgeable they are about the condition the more they will show bargainingacceptance of the baby hoping that the abnormality can be corrected.

Mothers who have other children tend to accept the situation better than first-time mothers. The mother with children has already proved that she is capable of giving birth to normal children (Cases 11, 12, 13, 16 and 19) while the first-time mothers may be keen to have another normal child in an effort to prove her ability to have normal children (Cases 10 and 14).

Most of the clients were from the lower socio-economic group (R200 per month or less), only one was a qualified, enrolled nurse who belonged to a relatively higher income group (R500 or more per month). Most of the mothers barely passed primary school education (Cases, 1, 2, 6, 8, 13 and 15). Only one mother had more than a form IV education. This factor limits the ability of staff to teach parents, since literature cannot be used.

\section{Conceptual Viewpoint of Parents}

\section{Most parents verbalised a Christian} perspective and attributed the abnormality to God but they also expressed the possibility of the traditional remedies being effective.

In the mind of the respondents western medicine is associated with a Christian perspective. Those respondents who have a positive outlook verbalised that God does as he wills and nobody has the right to question his authority. They see the abnormal baby as a gift from God. Those respondents who have a negative outlook assume that God is punishing them for some wrong they have done in the past and feel guilty about it.

Most mothers of older babies have been to traditional or faith healers even if they are professing Christians. When Western medicine fails, most respondents believe that things have gone wrong because they have abandoned their traditional cultural beliefs. They often attempt to go back and observe rr cultural obligations and perform rituals Inmonly prescribed to appease their ancestors.

Common causes of 'ancestors wrath' or 'ulaka lwabaphansi' identified in this study included:

- A male born out of wedlock using a maternal instead of his paternal surname (Case 13).

- A child who is not reported to the ancestor through the performance of special rituals 'Ukubikwa', particularly if he is of royal descent 'amakhosi' (Cases 18 and 19).

- An unmarried girl who damages have not been paid 'Inhlawulo' (Cases 9, 19 and 20).

— 'Umeqo' some imaginary traditional black magic line drawn through or sprinkled in an area to trap and harm the victim as organised by the person exercising this witchcraft. This specifically affects the person intended to be harmed only (Case 13).

- Where the parents have not offered a white goat skin to carry the baby on the back according to tradition 'imbeleko Yomntwana' (Case 18).
- 'Isihlambezo' a concoction prescribed as a mixture to facilitate labour pains. This may be suspected to be the cause of the abnormality.

\section{Common Traditional Solutions are Believed to Include}

Faith healers: These emphasize healing by prayer (Cases 12 and 16). They go to a place called 'eChibini' in Clermont Township. It is an Apostolic Faith mission believed to have members who heal by spiritual power using a lot of water to cleanse the evil spirits which have caused the mishap of an abnormal baby in the family. 'Chancele' is a place believed to be sacred in the Transkei which is reputed to have healing powers associated with religion and belief in holy water. They pray for water to be converted into holy water which is believed to have special powers of healing. Holy water consists of water and salt or water and ash. Zionists and some Apostolic religions are known to use holy water for dispelling evil spirits and for treatment. They combine the Western God with tactics unknown to the Western cultural belief system and therefore attributed to traditional Black culture (Cases 13 and 18) although the tactics are foreign to black cultures as well. These methods of faith healing are more acceptable to the less educated family groups than the pure Western religious systems.

Traditional healers: Parents go to a 'sangoma' a traditional medicine man, who is a specialist in diagnosing conditions, as well as 'inyangas', herbalists who focus on prescribing effective treatment and traditional medicine. 'Amagobongo' is a ritual carried out as a corrective measure to reverse the situation (Case 13).

\subsection{Available Support Systems}

The available support systems are inadequate. Those that exist do not function effectively for this population group. The available support systems mentioned by respondents include:

(a) single care grants

(b) hospitals

(c) clinics

(d) day care centres

(e) residential institutions

(f) mutual- and self-help groups and

(g) extended family groups

Although these support systems exist, there are serious problems with all of them.

\subsubsection{Single Care Grant}

These are not adequate because a physically handicapped child does not qualify for it. Only a severely mentally retarded child would qualify. The severity would be determined by the assessment made by specific health care workers. Even if the child qualifies, he has to be 3 years old before he can receive a grant. Secondly, the procedure followed when applying for this grant is so complex that it may be too expensive for some of these families to complete the application (Case $15)$.

\subsubsection{Hospital and Clinics}

Mothers of newborn babies are given the option to leave the baby in the hospital and go home (Case 11). Some are willing to do so if they are working parents while others refuse. Those who leave the baby in hospital do so with the idea that the baby will soon die. The baby may live for over a year (Case 11) and it may be difficult to transfer the child to a residential institution. The baby becomes too big to be kept in a bassinette and cot-beds are not available in the nursery. The concerned mother will have to visit the hospital frequently and this may be very costly and practically impossible. There is no organised support system to assist the mother under such circumstances.

Clinics are available at the centra! hospitals and as peripheral health care centres (rural clinics) but they are not effective in dealing with the problem adequately.

It is very expensive for parents from rural areas to bring their children for follow-ups every other month (Case 17). In this case the mother spent about R60 every 6 months to come to King Edward Hospital, where no specialist treatment is given, but she is just told to "come back in 6 months". There is great need to investigate and critically review the system of referral for better co-ordination.

\subsubsection{Day Care Centres}

These facilities are necessary for safe care and for stimulating the development of the child.

There are a few day care centres for physically and mentally handicapped children. The few available are not well organised for co-ordination. Daily transpon to and from visiting the child may present a problem (Case 11) and may not be readily available (Case 19). The day care centres may not be specialised for developing the specific skills of this handicapped baby. Some parents who were willing to send their babies to the day care centres indicated that there were no such centres (Cases 14, 18 and 19).

\subsubsection{Residential Institutions}

Parents appeared better adjusted if their babies were admitted in a residential institution (Cases 11, 12,14 and 16) than if they were taken care of at home (Cases 15 , $17 \mathrm{~m} 18$ and 19 ). There is only one residential institution and it is always full. Vacancies are available only when one of the children die because they are seldom discharged. Many of these children will live for a long time.

\subsubsection{Self-help Groups}

A few Blacks have been referred through their employers to the existing mutual- and selfhelp groups (Cases 18 and 19) but they have not yet interacted with this group meaningfully. They have received pamphlets which inform them of the group's existence but they have had problems getting to the meetings because of lack of transport. Religious support groups offer support through prayer meetings and through the moral support of members. These members do not necessarily have the same experience or specific skills to share with the group of mothers but they offer support and encouragement to the mothers to accept the baby as the will of God and a gift from him. They encourage a positive outlook. This group does function effectively particularly in the early stages of this misfortune. 


\section{ANNEXURE}

\section{ZULU TERMINOLOGY}

1. Amadlozi-ancestors.

2. Amakhosi-chiefs.

3. Amagobongo - a kind of calabash similar to the one used to ferment milk (maas) used for storing Zulu herbs. A ritual is carried out by killing a chicken or slaughtering a goat in the cleansing ceremony. This is carried out when one is being trained as a sangoma. Zulu herbs are used during this ritual.

4. Echibini - at a pond or dam - a holy area used by the members of the St. John Apostolic Faith Mission (at Clermont Township) believed to have special healing powers through the use of holy water.

5. Imbeleko yomntw'ana - a goat skin used to carry the baby on the back.

6. Isihlambezo - a herbal mixture taken by a pregnant woman to facilitate labour and believed to minimise labour pains.

7. Nozipho - pleural of Nosipho.

8. Ukubikwa - to be reported. A ritual carried out when a member of the family is being reported to the ancestors as newcomer either by birth or marriage.

9. Ulaka Lwabaphansi - ancestors wrath.

10. Umeqo - an imaginary area believed to have been treated through black magic so as to harm a specific individual. Swelling of the feet or other physiological problems are usually associated with this belief. Umeqo can be used interchangeably with 'Ukubekelwa'.

11. Inhlawulo - a penalty (usually a cow) paid by a young man for having made a girl pregnant.

12. Ukushweleza-to plead for the mercy of the ancestors.

\subsection{The Ethics of Abortion and Euthanasia} In the case of mothers of newborn babies most respondents ( 6 out of 20 ) indicated that they would not agree to either abortion or euthanasia because they were Christians and view killing as a sin. Mothers of older babies generally felt the same.

A few respondents ( 6 out of 20 ) indicated that it was only when they saw the nature and severity of the condition that they realised that it would have been better to have had a therapeutic abortion than to have had a grossly malformed baby. They confessed that they would have a therapeutic abortion in future pregnancies should they be diagnosed and be so advised by health care providers.

\begin{tabular}{|c|c|c|c|c|c|c|}
\hline Case* & $\begin{array}{l}\text { Mother's } \\
\text { Age (yrs) }\end{array}$ & $\begin{array}{l}\text { Marital } \\
\text { Status }\end{array}$ & $\begin{array}{l}\text { Parity } \\
\text { Gravida }\end{array}$ & $\begin{array}{l}\text { Baby's } \\
\text { Sex }\end{array}$ & $\begin{array}{l}\text { Home } \\
\text { Town }\end{array}$ & Baby's Diagnosis \\
\hline 1 & 22 & $\mathrm{u}$ & P2G2 & M & Eshowe & Intraventricular Haemorrhage \& Hydrocephalus \\
\hline 2 & 27 & $\mathbf{M}$ & P4G4 & $\mathbf{F}$ & Mahlabathini & Spina Bifida \\
\hline 3 & 26 & $\mathbf{u}$ & P4G4 & $\mathbf{M}$ & Kwandengezi & Myelomeningocoele \& Hydrocephalus \\
\hline 4 & 22 & $\mathbf{M}$ & P3G2 & $\mathbf{F}$ & Bizana & Co-joined Twins (Abdomen) \\
\hline 5 & 17 & $\mathbf{u}$ & PIGI & $\mathbf{F}$ & Transkei & Spina Bifida with Paralysis \\
\hline 6 & 21 & $\mathbf{u}$ & P2G2 & M & Mooi River & Spina Bifida \& Myelomeningocoele \\
\hline 7 & 24 & $\mathrm{u}$ & P3G3 & $M$ & Umlazi & Myelomeningocoele \& Hydrocephalus \\
\hline 8 & 28 & $\mathbf{M}$ & P3G3 & $\mathbf{F}$ & Harrismith & Cystic Hydroma of Lymphangloma \\
\hline 9 & 25 & $\mathrm{u}$ & P5G5 & $\mathbf{F}$ & Mandeni & Deformed Fused Legs (Mermaid) \\
\hline 10 & 18 & $\mathrm{U}$ & PIGI & $\mathbf{M}$ & KwaMashu & Myelomeningocoele \& Deformed Legs \\
\hline 11 & 19 & $\mathrm{M}$ & P2G2 & $\mathbf{M}$ & Clermont (Keh) & Di-Microcephaly \& Anencelphaly \\
\hline 12 & 56 & $\mathrm{M}$ & P8G8 & $\mathbf{M}$ & KwaMashu (Ekuhlengweni) & Down's Syndrome \\
\hline 13 & 23 & $\mathbf{M}$ & P2G2 & $\mathbf{M}$ & KwaMashu & Hydrocephalus \\
\hline 14 & 28 & $\mathrm{U}$ & P5G4 & $\mathbf{M}$ & KwaMashu (died) & Hydrocephalus \\
\hline 15 & $\begin{array}{l}\text { Mother died } \\
\text { Sister }\end{array}$ & & P8G8 & $\mathbf{M}$ & $\begin{array}{l}\text { KwaMakhutha } \\
\text { (Home) }\end{array}$ & Microcephaly \\
\hline 16 & 46 & $\mathbf{U}$ & P3G3 & M & Umlazi(Ekuhlengweni) & Hydrocephalus \\
\hline 17 & 38 & $\mathbf{M}$ & P6G6 & $\mathbf{F}$ & Kranskop (Home) & Hydrocephalus \\
\hline 18 & 29 & $\mathrm{u}$ & P2G2 & $\mathbf{M}$ & Redhill (Home) & Spina Bifida \\
\hline 19 & 24 & $\mathbf{U}$ & P2G2 & $\mathbf{F}$ & KwaMashu (Home) & Spina Bifida \\
\hline 20 & 26 & $\mathbf{M}$ & P3G3 & $\mathbf{F}$ & Tongaal (Home) & Spina Bifida \\
\hline $\begin{array}{l}\text { - Cas } \\
\text { Cas }\end{array}$ & 1 to 10 : nev & on ba & & & & \\
\hline
\end{tabular}

Two out of 10 respondents indicated that they would let the doctor decide whatever is best for the baby. They would agree to intervention whether therapeutic abortion or passive euthanasia if this was the decision made by health care providers.

In two cases the husband differed from the wife on the issue of abortion. In one case the husband would agree to abortion whilst the wife would refuse, and in the other case the reverse is true.

\section{CONCLUSION}

The very real need for a better planned and co-ordinated service to the Black families who have to care for severely handicapped children, was clearly demonstrated by this study. The battle with their own emotional and religious responses to the birth of this child, while having to cope with enormous physical and economic problems with extremely limited supportive services.

\section{REFERENCES}

Dorner, S. \& Atwell, J.D. Family adjustment to the early loss of a baby born with spina bifida. Developmental Medicine and Child Neurology 1985. August Vol. 27 (4) 461-466.

Kazak, Ann E. Family Stress and Social Suppor Networks: An analysis of families with handicapped children. Dissertation abstract
International 1985, February Vol. 45 (8B).

Mercer, R.T. Mothers' resspones to their infants with defects. Nursing Research, 197423 (2) 133 137

Romney, Martha C. Congenital defects: Implementation on family development and parenting. Issues in Comprehensive Pedeatric Nursing, 1984, Vol. 7 (1) 1-5.

Tumbull Ann P. Rutherford. Parents Speak Out: Growing with a handicapped Child. Charles E Mevril Publishing Company; July 1987

Venter Louis. An exploration of the needs of white mothers of physically handicapped children expressed by them and the relevance of these needs towards an evaluation of nursing care. Unpublished M.Soc.Sc. Thesis, University of Natal, 1986.

M. Susan Mabaso, M. Soc. Sc. (Nursing) University of Natal, Durban. Principal Tutor Natal College of Nursing: King Edward VIII Campus (College of midwifery)

Leana R. Uys D. Soc. Sc. University of the Orange Free State, Professor, Department of Nursing, University of Natal: Durban

This article is based on research done for the degree M.Soc.Sc. in the Department of Nursing, University of Natal: Durban. 